\title{
Effect of three months of periodized hydrogymnastics exercise program on urinary concentration of deoxypyridinoline in older women
}

Paulina Yesica Ochoa-Martínez', Javier Arturo Hall-Lopez', Francisco Argenix Pérez Ávila', Cristiano Andrade Quintão Coelho Rocha², Maria Helena Rodrigues Moreira ${ }^{2}$, Estélio Henrique Martin Dantas ${ }^{3}$

\begin{abstract}
Objective: To determine the effect of three months of periodized hydrogymnastics exercise program on urinary concentration of deoxypyridinoline in older women. Subjects and methods: Twenty-six subjects were randomly assigned in two, intervention group $(n=16)$ and control group $(n=10)$. The intervention group followed 12-week of periodized hydrogymnastics training program five times a week, 50 minutes of water exercise with work heart rate reserve of $40-50 \%$ (1- $6^{\text {th }}$ week) increasing the load to $50-60 \%$ (7-12 ${ }^{\text {th }}$ week); the control group was not involved in exercise and remained sedentary. The urinary concentration of deoxypyridinoline was evaluated by high resolution liquid chromatography using the reactive immulite pyrilinks-D siemens medical solutions, pretest at the baseline and at the end post-test of the 12-week of water-exercise. As statistical analyses mixed $2 \times 2$ ANOVA was used, also percentage changes $(\Delta \%)$ was calculated. Results: The results did not show significant improvement $(p<0.05)$ comparing the interaction intergroup and the measurements of urinary concentration of deoxypyridinoline $(p=0.504)$, percentage change $(\Delta \%)$ showed positive improvements in the experimental group of -13.7 ( $\mathrm{nM} / \mathrm{mMcreatine}$ ) in comparison with -7.1 (nM/mMcreatine) from the control group. Conclusion: The present study involves periodization increasing the load heart rate reserve of hydrogymnastics exercise in order to produce grater adaptations, but the results showed than is not possible to infer that hydrogymnastics is effective in increase urinary concentration of deoxypyridinoline in older women, will be appropriated in the future more studies to better clarify the possibilities of improvements between hydrogymnastics and urinary concentration of deoxypyridinoline. Arch Endocrinol Metab. 2015;59(6):523-7
\end{abstract}

Autonomous University of Baja California, Faculty of Sports, Mexico 2 University Tras-os-Montes and Alto Douro, Department of Sport Sciences, Portugal ${ }^{3}$ Federal University of State of Rio de Janeiro and Tiradentes, Laboratory of Human Motricity Biosciences, Rio de Janeiro, RJ, Brazil

Correspondence to: Javier Arturo Hall-Lopez Río Mocorito y Monclova Street s/n, Ex ejido Coahuila Neighborhood 21280 - Mexicali Baja California Mexico

javierhall@uabc.edu.mx

Received on May/12/2015 Accepted on July/31/2015

DOI: 10.1590/2359-3997000000102

\section{Keywords}

Bone density; older women; exercise; osteoporosis; physical activity

\section{INTRODUCTION}

$\mathrm{P}$ ost-menopausal in women is an aging natural process characterized for gradual reduction in the release of estrogen associated with several morphofunctional changes ( 1 ), these changes include a decrease in bone microarchitecture mass than produce osteoporosis (2), there is scientific evidence pointing than presence of osteoporosis in post-menopausal women coincides with incidence of fall related injuries and bone fractures $(3,4)$, moreover, osteoporosis in post-menopausal in women has been identified as a disease that decrease the physical fitness, independence of movement and functional autonomy in completing activities of daily living (5), which affect the social development and decrease the quality of life (6).
Evidence from systematic review and meta-analysis clearly show than physical exercise induce an improvement bone mass content in older women (7-9). Controlled trials in post-menopausal women have been considered physical exercise along with medication and diet one of the three cornerstones of osteoporosis $(10,11)$. By other hand, there are different accepted diagnostic criteria to identify osteoporosis than may partly explain the variability of prevalence (12); also the incidence of physical exercise to induce changes in bone metabolism is determined for the duration, intensity and type of exercises (9).

The deoxypyridinoline has been identified as a good prediction by early change of bone metabolic markers of the efficacy of anti-osteoporotic drugs on bone mass in osteoporotic patients (13-16). 
Physical exercise in modalities such as aerobic, strength and electro stimulation exercises showed positive results in bone mineral density assessed by dual-energy X-ray and biochemical markers of bone turnover (osteocalcin, alkaline phosphatase, pyridinoline, and deoxypyridinoline) thus preserving the bone health in elderly (17-19).

However, is not yet fully clarified which would be the best modality, duration, frequency of physical exercise to contribute with bone health evaluated by methods as biochemical markers of bone turnover to verify in a short time curse the efficacy of exercise. To the best of our knowledge there is a lack references than report the incidence of the hydrogimnastic on urinary concentration of deoxypyridinoline in older women. To diminish this feature, this research considered the hydrogimnastic than carried out through realizing rhythmic-gymnastic activities in an aquatic environment (20), this modality of exercise is especially recommended among people who have limitations with do exercise on dry land due to impact (21) and which in the last ten years, has taken popularity and preference among elderly by taking advantage of water properties in order to provide fluidity and a wider range in movements while diminishing the risk of injuries (20). It was found than water exercise in older women provides positives effects on bone and physical function of postmenopausal women $(9,22)$. In this context, in exercise training periodization increasing the load heart rate reserve has been produce grater adaptations (23). The present study involves a periodized hydrogymnastics training program with different frequency, work load intensity and time than other references $(9,22)$. Thus, the aim of this study was to determine the effect of three months of periodized hydrogymnastics exercise program on urinary concentration of deoxypyridinoline in older women.

\section{SUBJECTS AND METHODS}

\section{Subjects}

Twenty-six elderly women volunteered to partake in the hydrogimnastic program in the aquatic complex of the Faculty of Sports at the Autonomous University of Baja California, accordingly this study focused on older women, exclusion criteria included, not have ambulation capacity, have performed a systematical routine of exercise in the previous six months, to possess any sort of acute or chronic complication that would hinder wa- ter exercise, such as heart problems, diabetes mellitus, hypertension or asthma; physical complications that could affect the ability to accomplish exercise such as osteoarthritis, joint injuries or recent bone fractures, psychological and neurological problems or have been taking medicine to treat osteoporosis

The present study followed the ethical principles regarding human experimentation proposed by the Helsinki declaration; all the subjects provided a written consent in order to participate in the study (24), that was approved by the research program of the Faculty of Sports of the Autonomous University of Baja California. Protocol \# 149/2/C/13/16.

\section{Study design and testing procedures}

Participants were randomly assigned in two, water exercise intervention group $(\mathrm{n}=16$, age of $67.5 \pm 5.4$ years) and non-exercising control group ( $\mathrm{n}=10$, age of $67.4 \pm 4.7$ years) who advised not to join in systemized exercise but to continue with their usual daily physical activities.

In order to determine the evaluation of the dependent variable, urinary concentration of deoxypyridinoline, was performed using the following procedures: a 2-hour fasting morning urine sample was collected at the same time of the day to assess urinary excretion of deoxypyridinoline; the quantifications of urinary concentration of deoxypyridinoline $(\mathrm{nM} / \mathrm{mMcreatine})$; it was determined by high resolution liquid chromatography using the reactive immulite pyrilinks-D siemens medical solutions (15); this peptide represents link between collagen molecules, more specifically between their amino and carboxy terminal portions, being released when there bone destruction, its main indication is marker of bone in osteoporosis catabolism, thereby demonstrating greater specificity than other markers of bone resorption (13); the reference values of the results were distributed according to sex and age, and for women the change occurs between 2.5 to $7.4 \mathrm{nM} /$ mMcreatine (15). Measurements were performed at the baseline pretest and immediately upon posttest of the 12 -week of water-exercise, only those completing $95 \%$ of training adherence were included in the statistical analysis.

\section{Periodized hydrogimnastic training}

The water exercise was conducted and supervised by master in sport science specialist also in accordance with 
physical exercise prescription for older adults established by the American College of Sports Medicine (25). The participants completed three-month of periodized hydrogimnastic training program five times a week, with 50 minutes per session which was comprised by 10 minutes of warm-up, 30 minutes of water exercise training component with intensity monitored by telemetry using a heart rate monitor Polar FT7 ${ }^{\circledR}$ (Finland), the work heart rate reserve of $40-50 \%$ ( $1-6^{\text {th }}$ week) increasing the load to $50-60 \%$ heart rate reserve $\left(7-12^{\text {th }}\right.$ week) the work heart rate reserve was estimated with the equation Max HR = 208-0.7x age (26), followed by 10 minute of cool down.

\section{Statistical analysis}

Statistical analyses were performed using statistical software SPSS for Windows version 20 (IBM Corporation, New York, USA). Mean (M) and $( \pm$ SD) standard deviation were obtained to calculate the dependent variables; Shapiro-Wilk Test was used in order to determine the normality of the groups and the homogeneity of the sample. Differences inter and intragroup pretest-posttest were determined using mixed 2 x 2 ANOVA (groups $\mathrm{x}$ measurements), the significance level were performed of $\mathrm{p}<0.05,95 \%$ probability of accuracy of the results or negative event with a probability of $5 \%$ per case. Also percentage changes $(\Delta \%)$ were calculated for each study group [(Media post - Media pre)/Media pre] x 100.

\section{RESULTS}

Descriptive statistical $(\mathrm{M} \pm \mathrm{SD})$ of anthropometric variables and urinary concentration of deoxypyridinoline are presented in table 1 , the values showed lower means in experimental group than in control group at the baseline pretest than posttest of the 12 -week of hydrogimnastic.
As sown in figure 2 , the percentage changes $(\Delta \%)$ of exercise group attained lower values after treatment.

Changes in the urinary concentration of deoxypyridinoline $(\mathrm{M} / \mathrm{mMcreatine})$ among the participants of the study $(\mathrm{n}=26)$.

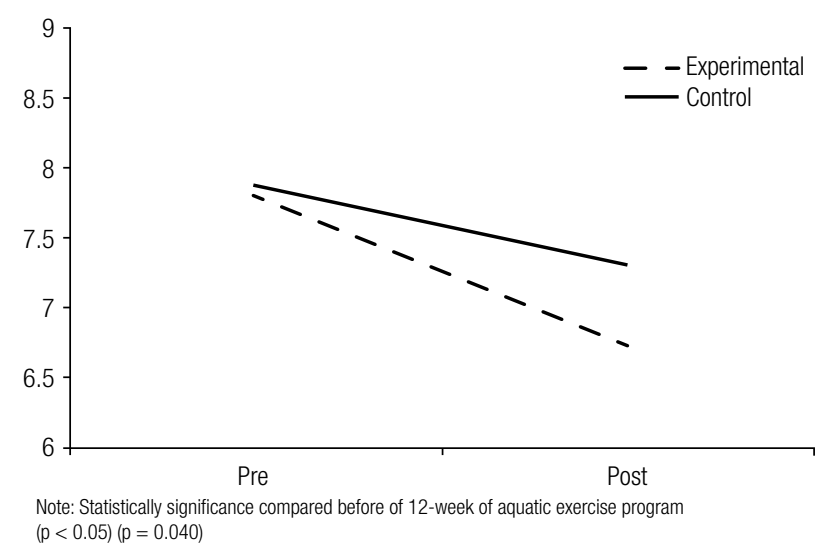

Figure 1. Provides the data of the mixed $2 \times 2$ ANOVA (groups $x$ measurements) analysis showed significant values $(p<0.05)$, the results indicated no statistically significant interactions existed $(p=0.504)$ between the groups and the measurements, neither statistically significant changes were found between groups $(p=0.639)$ but it showed statistically significant on the measurements $(p=0.040)$.
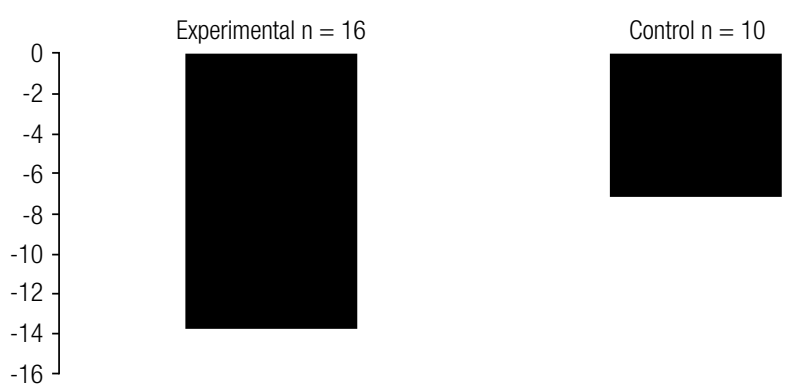

Figure 2. Percentage changes $(\Delta \%)$ in the urinary concentration of deoxypyridinoline (M/mMcreatine) among the participants of the study ( $\mathrm{n}$ $=26)$.

Table 1. Descriptive statistics ( $M \pm S D)$ of the volunteer women in the study $(n=26)$

\begin{tabular}{|c|c|c|c|c|}
\hline \multirow{2}{*}{ Variables } & \multicolumn{2}{|c|}{ Experimental $(n=16)$} & \multicolumn{2}{|c|}{ Control $(n=10)$} \\
\hline & Pre & Post & Pre & Post \\
\hline \multicolumn{5}{|l|}{ Anthropometric } \\
\hline Weight (kg) & $74.09 \pm 10.74$ & $73.27 \pm 10.81$ & $76.26 \pm 15.17$ & $76.29 \pm 15.70$ \\
\hline Height (cm) & $155.95 \pm 5.78$ & $155.90 \pm 5.72$ & $153.20 \pm 5.86$ & $152.41 \pm 6.19$ \\
\hline BMl $\left(\mathrm{kg} / \mathrm{m}^{2}\right)$ & $30.53 \pm .9$ & $30.16 \pm 4.55$ & $32.60 \pm 6.91$ & $32.97 \pm 7.19$ \\
\hline \multicolumn{5}{|l|}{ Dependent } \\
\hline $\mathrm{nM} / \mathrm{mMcreatine}$ & $7.81 \pm 1.70$ & $6.74 \pm 1.49$ & $7.87 \pm 2.41$ & $7.31 \pm 2.08$ \\
\hline
\end{tabular}

Note: Statistically signicance compared before of 12-week of aquatic exercise program

$(p<0.05)(p=0.040)$ 


\section{DISCUSSION}

The main findings of the present research were that twelve weeks of periodized hydrogimnastic training program not improve significant reductions of urinary concentration of deoxypyridinoline, in spide of percentage change $(\Delta \%)$ showed positive improvements in the experimental group of -13.7 ( $\mathrm{nM} / \mathrm{mMcreatine})$ in comparison with $-7.1(\mathrm{nM} / \mathrm{mMcreatine})$ from the control group.

In spite of the hydrogimnastic training program in these research was designed five times a week whit periodization in order to produce grater adaptations (23), increasing the load heart rate reserve of $40-50 \%\left(1-6^{\text {th }}\right.$ week) increasing the load to $50-60 \%$ heart rate reserve $\left(7-12^{\text {th }}\right.$ week $)$ these result was not consistent with a controlled trial than evaluate with biochemical markers of bone turnover in elderly who practice aquatic exercise than showed serum osteocalcin, intra and intergroup statistical differences of $\mathrm{p}=0.042$ and $\mathrm{p}=0.027(22)$, other study than showed benefits in bone formation marker assessed by procollagen type 1 amino-terminal propeptide $(15.8 \% ; \mathrm{p}=0.001)$ after a high-intensity of aquatic exercise program in postmenopausal women (27); these discrepancies with our results may be owing to de time than were performed through 24 weeks of aquatic exercises but with lower frequency ( 3 times a week) and lower work load intensity by other hand some of these programs where attendance in strength modalities in to the water than may have influence the improvements in bone turnover $(9,27)$.

Regarding the assessment of osteoporosis in elderly population urinary concentration of deoxypyridinoline was chosen for inexpensive, validated, easy to apply bone marker which have been identified as a good prediction by early change of bone metabolic markers of the efficacy of anti-osteoporotic drugs on bone mass in osteoporotic patients (13-16). Strength exercise modalities have been showed better results in in biochemical markers of bone turnover $(17,19,28)$ due the voluntary muscle contraction produces stress on bone morphology and the mechanical load resulting from the muscle contraction induced osteoblast formation and inhibits bone resorption (9) instead of aquatic exercises where the reduction of the gravity forces on human body when immersed in water makes and low high impact seem to be less osteogenic (29).

In geriatrics, gerontology and physical exercise areas, has been proposed during the rehabilitation of oste- oporosis disease in order to minimize physical disability and fall accidents (3), due the release of estrogen in post-menopausal women bone metabolic markers as urinary concentration of deoxypyridinoline (30) should be monitored to distinguish the effects of more than 24 weeks of hydrogimnastic training in older women as a non-pharmacological intervention.

Although this study had limitations, by the sample size and did not control the diet as a co variable, our data seem to be of importance in may contribute to better understanding for health professionals when assessing urinary concentration of deoxypyridinoline to plan and control workloads in hydrogimnastic training programs. However in the future, it will be appropriated more studies to better clarify the underlying mechanism between hydrogimnastic and urinary concentration of deoxypyridinoline.

Acknowledgements: the research was funded by internal call number $16^{\text {th }}$ of research project from the Autonomous University of Baja California UABC; Grant 149/2/C/13/16.

Disclosure: no potential conflict of interest relevant to this article was reported.

\section{REFERENCES}

1. Fulop T, Larbi A, Witkowski JM, McElhaney J, Loeb M, Mitnitski A, et al. Aging, frailty and age-related diseases. Biogerontology. 2010;11(5):547-63.

2. Laurent Benhamou C. Bone ultrastructure: evolution during osteoporosis and aging. Osteoporos Int. 2009;20(6):1085-7.

3. Lippuner K. [Epidemiology of osteoporotic fractures in Switzerland]. Rev Med Suisse. 2009;5(207):1304-8.

4. Pinheiro Mde M, Eis SR. Epidemiology of osteoporotic fractures in Brazil: what we have and what we need. Arq Bras Endocrinol Metabol. 2010;54(2):164-70.

5. Tom SE, Adachi JD, Anderson FA Jr, Boonen S, Chapurlat RD, Compston JE, et al. Frailty and fracture, disability, and falls: a multiple country study from the global longitudinal study of osteoporosis in women. J Am Geriatr Soc. 2013;61(3):327-34.

6. Darba J, Kaskens L, Perez-Alvarez N, Palacios S, Neyro JL, Rejas J. Disability-adjusted-life-years losses in postmenopausal women with osteoporosis: a burden of illness study. BMC Public Health. 2015;15:324.

7. Ma D, Wu L, He Z. Effects of walking on the preservation of bone mineral density in perimenopausal and postmenopausal women: a systematic review and meta-analysis. Menopause. 2013;20(11):1216-26.

8. Babatunde OO, Forsyth JJ. Quantitative Ultrasound and bone's response to exercise: a meta analysis. Bone. 2013;53(1):311-8.

9. Moreira LD, Oliveira ML, Lirani-Galvao AP, Marin-Mio RV, Santos RN, Lazaretti-Castro M. Physical exercise and osteoporosis: effects of different types of exercises on bone and physical function of postmenopausal women. Arq Bras Endocrinol Metabol. 2014;58(5):514-22.

10. Muraki S. [Diet, exercise and bone metabolism]. Clin Calcium. $2011 ; 21(5): 715-9$. 
11. Maeda SS, Lazaretti-Castro M. An overview on the treatment of postmenopausal osteoporosis. Arq Bras Endocrinol Metabol. 2014;58(2):162-71.

12. Silva BC, Bilezikian JP.Trabecular bone score: perspectives of an imaging technology coming of age. Arq Bras Endocrinol Metabol. 2014;58(5):493-503.

13. Vieira JG. Considerações sobre os marcadores bioquímicos do metabolismo ósseo e sua utilidade prática. Arq Bras Endocrinol Metabol. 1999;43(6):415-22.

14. Dreyer P, Vieira JG. Bone turnover assessment: a good surrogate marker? Arq Bras Endocrinol Metabol. 2010;54(2):99-105.

15. Yu SL, Ho LM, Lim BC, Sim ML. Urinary deoxypyridinoline is a useful biochemical bone marker for the management of postmenopausal osteoporosis. Ann Acad Med Singapore. 1998;27(4):527-9.

16. Pardini DP, Sabino AT, Meneses AM, Kasamatsu T, Vieira JG. Effect of hormone replacement therapy on the bone mass and urinary excretion of pyridinium cross-links. Sao Paulo Med J. 2000;118(1):3-6.

17. Korpelainen R, Keinanen-Kiukaanniemi S, Heikkinen J, Vaananen $\mathrm{K}$, Korpelainen J. Effect of impact exercise on bone mineral density in elderly women with low BMD: a population-based randomized controlled 30-month intervention. Osteoporos Int. 2006;17(1):109-18.

18. Bergstrom I, Landgren B, Brinck J, Freyschuss B. Physical training preserves bone mineral density in postmenopausal women with forearm fractures and low bone mineral density. Osteoporos Int. 2008;19(2):177-83

19. Kemmler W, von Stengel S. Exercise and osteoporosis-related fractures: perspectives and recommendations of the sports and exercise scientist. Phys Sportsmed. 2011;39(1):142-57.

20. Kamioka H, Tsutani $\mathrm{K}$, Okuizumi H, Mutoh Y, Ohta M, Handa S, et al. Effectiveness of aquatic exercise and balneotherapy: a summary of systematic reviews based on randomized controlled trials of water immersion therapies. J Epidemiol. 2010;20(1):2-12.
21. Kamioka H, Tsutani K, Mutoh Y, Okuizum H, Ohta M, Handa S, et al. A systematic review of nonrandomized controlled trials on the curative effects of aquatic exercise. Int J Gen Med. 2011;4:239-60.

22. Pernambuco CS, Borba-Pinheiro CJ, Vale RG, Di Masi F, Monteiro PK, Dantas EH. Functional autonomy, bone mineral density (BMD) and serum osteocalcin levels in older female participants of an aquatic exercise program (AAG). Arch Gerontol Geriatr. 2013;56(3):466-71.

23. Stanley J, Peake JM, Buchheit M. Cardiac parasympathetic reactivation following exercise: implications for training prescription. Sports Med. 2013;43(12):1259-77.

24. Puri KS, Suresh KR, Gogtay NJ, Thatte UM. Declaration of Helsinki, 2008: implications for stakeholders in research. J Postgrad Med. 2009;55(2):131-4.

25. American College of Sports M, Chodzko-Zajko WJ, Proctor DN, Fiatarone Singh MA, Minson CT, Nigg CR, et al. American College of Sports Medicine position stand. Exercise and physical activity for older adults. Med Sci Sports Exerc. 2009;41(7):1510-30.

26. Tanaka H, Monahan KD, Seals DR. Age-predicted maximal heart rate revisited. J Am Coll Cardiol. 2001;37(1):153-6.

27. Moreira LD, Fronza FC, Dos Santos RN, Zach PL, Kunii IS, Hayashi LF, et al. The benefits of a high-intensity aquatic exercise program (HydrOS) for bone metabolism and bone mass of postmenopausal women. J Bone Miner Metab. 2014;32(4):411-9.

28. Moreira LDF, Fronza FCAO, dos Santos RN, Teixeira LR, Kruel LFM, Lazaretti-Castro M. High-intensity aquatic exercises (HydrOS) improve physical function and reduce falls among postmenopausal women. Menopause. 2013;20(10):1012-9.

29. KohrtWM, Barry DW, Schwartz RS. Muscle forces or gravity: what predominates mechanical loading on bone? Med Sci Sport Exer. 2009;41(11):2050-5.

30. Bandeira F, Costa AG, Soares Filho MA, Pimentel L, Lima L, Bilezikian JP. Bone markers and osteoporosis therapy. Arq Bras Endocrinol Metabol. 2014;58(5):504-13. 